\title{
Integrated production logging tools approach for convenient experimental individual layer permeability measurements in a multi-layered fractured reservoir
}

\author{
Afshin Davarpanah ${ }^{1}\left[\right.$ [ Behnam Mirshekari ${ }^{1} \cdot$ Taraneh Jafari Behbahani $^{2} \cdot$ Mahmoud Hemmati $^{1}$
}

Received: 3 April 2017 / Accepted: 5 December 2017 / Published online: 4 January 2018

(c) The Author(s) 2018. This article is an open access publication

\begin{abstract}
Appropriate estimation of permeability is considered as one of the significant concerns of petroleum industries. Due to the growing demand for hydrocarbon fossil fuels in numerous industries, Petroleum Engineers always try to provide holistic and sustainable solutions to measure this parameter more accurately and to calculate the proper original oil in place (OOIP) and initial reserve. Hence, this accuracy estimation helps engineers whether the production and exploration operations are profitable or not and it might virtually eliminate the unnecessary expenditures. The term production logging tools (henceforth; PLT) involve a wide variety of measurement tools and many sensors. It, too, carries interpretation tools which evaluate the formation properties, in respect of the way PLTs would analyze the formation fluid movements inside and outside of the wellbore and subsequently estimate the production flow rate for each layer. On the other hand, it gives production and completion engineers the chance to investigate the appropriate efficiency of production and perforation processes to organize the remediation methodologies or preplan proper designing for modifying completion procedures which have based on the production logging tools interpretation. The purpose of this comprehensive research is to compare two different techniques (PLT and core analysis) of permeability measurement in a six-layered fractured reservoir and subsequently normalize each parameter to obtain the proper estimation. As a result, according to the evaluation of each technique, the amount of permeability in the layers 1,2,3, and 5 is relatively close to each other. Furthermore, regarding higher expenses of core analysis tests and the reliability of PLTs according to the results of this paper in the four out of six individual layers, Emeraude software by utilizing PLT interpretation could be a substitution and preferable methodology instead of core analysis measurements.
\end{abstract}

Keywords Production logging tools $\cdot$ Permeability measurements $\cdot$ Core analysis $\cdot$ OOIP $\cdot$ Reserve $\cdot$ Individual layers $\cdot$ Fractured reservoir

\section{List of symbols}

AOF Specific productivity index, STB/day/psi/ft

$B_{o} \quad$ Oil formation volume factor, BBL/STB

K Permeability, md

$M_{u} \quad$ Viscosity, $\mathrm{Cp}$

$P_{\text {avg }} \quad$ Average pressure in external borders, Psi

$P_{e} \quad$ External borders pressure, Psi

PLT Production logging tools

PI Productivity index, dimensionless

Afshin Davarpanah

Afshin.Davarpanah@ srbiau.ac.ir

1 Department of Petroleum Engineering, Science and Research Branch, Islamic Azad University, Tehran, Iran

2 Research Institute of Petroleum Industry (RIPI), P.O. Box 14665-1998, Tehran, Iran
$P_{\text {wf }} \quad$ Wellbore pressure for flowing well, Psi

$Q \quad$ Flow rate according to standard condition, STB/ day

$R_{e} \quad$ Distance from well center to external border, in

$r_{w} \quad$ Well center distance to wellbore, in

$\mathrm{S} \quad$ Skin effect, dimensionless

$\varnothing \quad$ Porosity, $\%$

$H_{c} \quad$ Hydraulic content, dimensionless

$r_{p} \quad$ Assume radius pipe, $\mathrm{ft}$

\section{Introduction}

Permeability is the constant proportionality parameter in Darcy's law, which relates discharge (flow rate) and fluid physical properties (e.g., viscosity) to a pressure gradient which applied to the porous media (Adeboye et al. 2012; 
Haro 2004; Rafik and Kamel 2017). The flow mechanisms pattern, especially in tight reservoirs like fractured reservoirs, should take into consideration. However, having said this, high amount of permeability will occasionally allow the reservoir fluids to move rapidly through rocks, and it utterly depended on the reservoir characteristics and other phenomena which significantly impact the permeability. Regarding the micro- or nanopores of these reservoirs, such parameters entailed fluid properties (e.g., fluid velocity) and pressure gradient which they exert a profound impact on the fluid mobilization in the cracks and subsequently lead to increase in the permeability. Thereby, the fluid flow in the small pores and these cracks is a bit different from the traditional Darcy's law in conventional reservoirs. Although some researchers believe that the phenomenon of low-velocity non-Darcy flow is the principal cause of fluid movement in the small pores, there are no comprehensive and systematic investigations to elaborate this issue appropriately. Furthermore, it needs to be more specific and accurate (Kaitna et al. 2016; Muljadi et al. 2016; Wang and Sheng 2017). Huang et al. (2013) proposed low-velocity non-Darcy flow schematically to show the considerable influence of pressure gradient and low velocity and consequently its impact on the fluid flow. As can be seen in Fig. 1 at a significant amount of pressure gradient, pressure gradient and fluid velocity have an increasing linear pattern, even though, in the small pressure gradient due to the absence of fluid flow, it has not any fluid velocity. Therefore, pressure gradient parameter and fluid velocity are considered as the principal factor in the fluid mobilization; in respect of the way, by increasing the pressure gradient rather than threshold pressure gradient (henceforth; TPG), the fluid would flow. Moreover, if the pressure gradient rises dramatically, the flow rate has a steep rise. Finally, it approximately seems a linear relationship as same as Darcy's law (Huang et al. 2016; Huang et al. 2013; Xiong et al. 2017). The proper amount of threshold pressure gradient is showed by PTPG. Prada and Civan (1999)

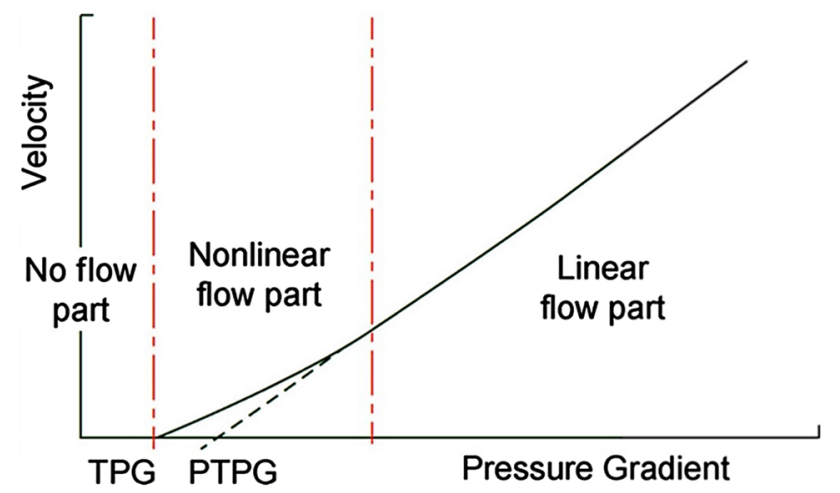

Fig. 1 A typical schematic of low-velocity Non-Darcy flow. (Reproduced with permission from Huang et al. 2013) proposed their research based on the utilization of brine in the measurement of pressure gradient versus fluid velocity. They go on to argue that fluid mobility reduction causes to decrease the pressure gradient; that is to say that the higher value of rock permeability and higher amount of fluid velocity, the smaller amount of PTPG (Kundu et al. 2016; Prada and Civan 1999).

The amount of permeability in sandstone layers may change between less than one up to more than 50,000 milliDarcy $(\mathrm{mD})$. The average amount of this parameter varied in the range of ten milli-Darcy to thousands of milli-Darcy regarding the types of reservoir and interconnection between cracks and fractures. The concept of permeability measurement is of importance in detecting the fluid flow properties of a reservoir such as hydrocarbons and aquifers (Aigbedion 2007; Dale 1949; Denney 2007; Feng et al. 2017; Lee and Bauer 2016). The permeability measurements through a reservoir were first explained by an empirical correlation which was called Darcy correlation by utilizing the water flow rate through a sand filter in 1856 by Henry Darcy:

$Q=\frac{K A}{L}\left(h_{2}-h_{1}\right)$,

where $Q$ is the volumetric flow rate through a sand pack, $K$ is the constant proportionality parameter in Darcy's law, $h_{2}, h_{1}$ are the hydrostatic heads at the sand pack inlet and outlet, respectively, and $A$ is the cross-sectional area. Later investigations determined that Darcy's law could be extended to other liquids and that the proportionality constant $K$ could be replaced by $K / \mu$, where $K$ is the permeability of the rock and $\mu$ is the viscosity of the fluid flowing through the rock. With this modification, Darcy's law can be written in a form suitable for our experiment as:

$Q=-\frac{0.00127 K A}{\mu l} \Delta P$,

where $\mu$ is absolute viscosity and $\Delta P$ is the pressure drop.

To calculate average permeability, weighted-average permeability, harmonic-average permeability, and geometricaverage permeability techniques are derived from experimental evaluations (McCain et al. 2011). The method of calculating average permeability used in this research in the section of core analysis is weighted-average permeability. This averaging process is used to determine the average permeability of layered-parallel beds with different permeabilities. Dealing with the coherent diagenetic and depositional complexity of carbonated reservoirs is considered as one the main challenges of petroleum industries for several decades. Thereby, engineers try to find novel solutions by using harnessing technologies to reduce vast sums of money which they spent for measuring reservoir properties. Wireline logging tools may confidentially provide a reasonable solution 
for obtaining the proper value of porosity and fluid saturation; nevertheless, in the case of permeability measurements, it may be debatable. Furthermore, core plugs are not the best candidate tools to measure the characterization of fractured and vuggy intervals (Ali Ahmadi et al. 2013; Frash et al. 2016; Sullivan 2007). Evaluating the appropriate properties of each layered reservoirs is considered as the underlying issues of engineering and geological perspectives. Also, determining the proper value of these crucial parameters exerts a profound impact on the primary and secondary oil recovery procedures, where the different layer permeabilities may lead to differential depletion. There are a wide variety of applied techniques to estimate the amount of permeability in the layered reservoirs in which the most important ones are core analysis, sidewall samples, wireline logging correlations, NMR logs, wireline formation testers, drill stem tests (DST), and production logging tools (Amir Shah et al. 2017; Kading 1976; Qobi et al. 2000; Quintero et al. 1999; Sætrom et al. 2016).

\section{Production logging tools}

Utilization of production logging tools in the horizontal and vertical wells is challenging regarding the deviation of the wells, complex conditions of the wellbore and multiple flow regimes. The first administration of production logging tools such as temperature, flowmeters, and density logging tools applied in the petroleum industries since the 1950s. In the coming decades, optimizing the well performances and managing the reservoir production are the most priorities of each company to provide the requirements to assess more contact with the production layers. Hence, the oil recovery factor has dramatically increased, and it gives engineers a chance to produce more volume of initial oil in place. As new production logging tools became available, interpretation methods evolved for the more complex flow conditions being encountered. These tools involved a series of records which illustrate the fluid behavior and nature of the reservoir during the production and injection procedures of an oil formation. Figure 2 shows the production logging tools components schematically (Frooqnia et al. 2011; Grayson et al. 2002; Hoffman and Narr 2012; Li and Zhao 2014; Plastino et al. 2017; Sullivan 2007).

One of the chief aims of production logging tools is to analyze and investigate the borehole performances like dynamic or static situation of a production well, measure the amount of productivity and injectivity index of zones or layers of a field, monitor the borehole inefficiencies by interpreting obtained logs, diagnose the effectiveness of stimulation or completion processes, and measure the physical condition of a well (Aghli et al. 2016; Al-Mulhim et al. 2015). Production logging tools are one of the leading operating services especially for cased-hole drilling, which entails

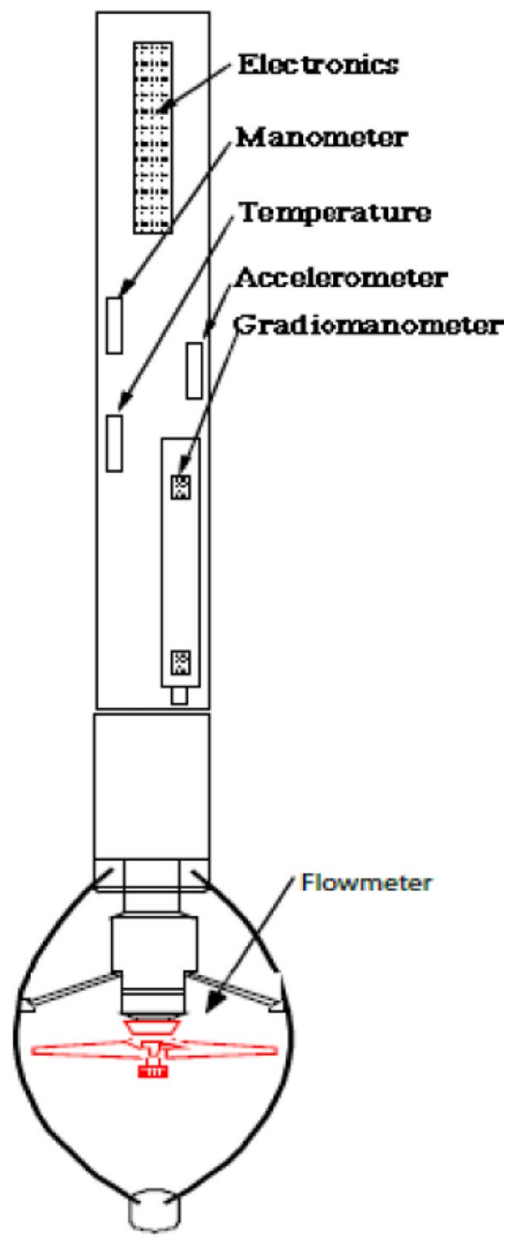

Fig. 2 Production logging tools components

monitoring the cement displacement, pipeline corrosion, and contacts. Moreover, it has been utilized in the setting of the packers, plug equipment, and perforation procedures. The most exceptional appeal of using production logging tools is to diagnose the problems which are caused by production operations such as leakage and occurring crossflow through the wellbore. There are many ways and techniques to obtain the measurement of the formation's fluid viscosity; however, it could be estimated by spinner flowmeter (a rotational blade which will turn when the reservoir fluid moves through the edges and past it). In ideal conditions, the rotational speed of the blade in revolutions per second (RPS) is proportional to the fluid velocity. Figures 3 and 4 show a schematic basis of two new production logging tools (Miklashevskiy et al. 2017).

Various types of production logging tools are listed below:

- Temperature logging

- Radioactive tracer logging

- Noise logging 
Fig. 3 General views of capacitance array tool (CAT)

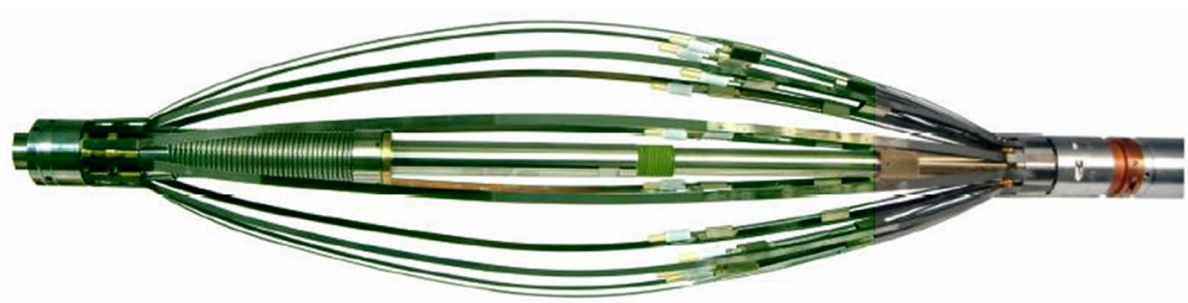

Fig. 4 General view of spinner array tool (SAT)

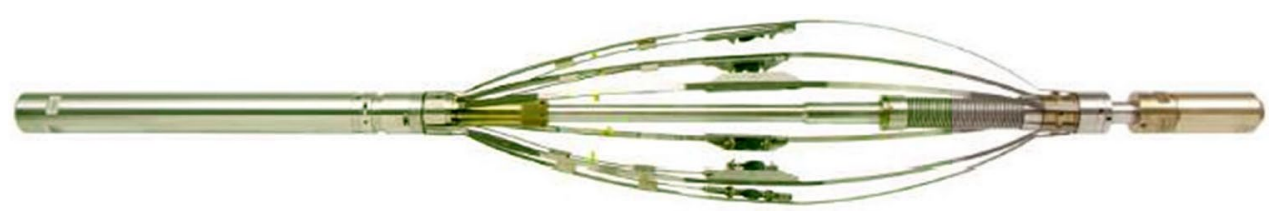

- Focused gamma ray density logging

- Unfocused gamma ray density logging

- Fluid capacitance logging

- Fluid identification logging in high-angle wells

- Continuous and full-bore spinner flowmeters

- Diverting spinner flowmeter

Some of the main applications of production logging tools are determination of well mechanical problems, analysis of the efficiency of completion processes, observation and monitoring of the profiles of production and injection scenarios, obtainment of the reservoir characteristics, and detection of cemented channels (Gan et al. 2016; Wilson 2016). According to the wide variety of $\log$ s which plotted in the Emeraude software, an empirical correlation for permeability estimation is described as Eq. 3. In this equation, fluid flow profile is considered for each meter $(h=1)$ (Galvao and Guimaraes 2017; Sullivan 2007; Williams 2016)

$k_{\mathrm{plt}}=\frac{c * q_{i} * \mu_{o} * \beta_{o}}{\left(p_{e}-p_{\mathrm{wf}}\right)}\left[\operatorname{Ln}\left(\frac{r_{d}}{r_{w}}\right)+s^{\prime}\right]$,

where $C$ is the constant volume of the equation, $q_{i}$ is obtained fluid flow from Emeraude software, $\mu_{o}$ is the viscosity, $P_{e}$ is the external pressure, $P_{\mathrm{wf}}$ is the internal well pressure, $S$ is skin factor, $B_{o}$ is oil formation volume factor, $r_{d}$ is depleted wellbore radius, and $r_{w}$ is wellbore radius.

Although there is excellent petroleum company's interest, numerous investigations have been conducted about the considerable influence of production logging tools on the reservoir characteristics measurement, and many experimental evaluations are widely reported in literature to estimate the permeability, in this analytical study, we concentrate on the administration of production logging tools advancements and import the obtained data from its $\log$ s to the Emeraude software. Therefore, Emeraude software simulates the operating procedures and well logging data to estimate permeability in each layer individually, and then it compares with the permeability which obtained from core analysis for each section. Furthermore, according to the recent studies which are based on the simulations of reservoir behavior by production logging tools and how to analyze them accurately, this extensive evaluation from Emeraude software offers enormous opportunities for petroleum companies to simulate the reservoir models on the software instead of core analysis and subsequently, it virtually eliminates the unnecessary expenditures of core plugging, and it's outrageous expenses of laboratory investigations.

\section{Methodology of work}

\section{Emeraude software}

Emeraude software was one of the applied petroleum engineering softwares from Kappa Company to interpret logging data. One of the chief aims of this software is to analyze the production logging tools data and simulate production profile to estimate the permeability. Nowadays, especially logging service companies use this software for interpreting the different logs which have been taken from the wellbore, and it is also compared to the core data (Cui et al. 2016; Haoua et al. 2015). There are several production logging tools in the Emeraude software which any of them has a specific interpretation. For example, flowmeter log (CFB) is used to determine the reservoir areas, evaluate the well stimulation operations, and facilitate the calculation of absolute open flow (AOF) and selective inflow performance by estimating the permeability. Another significant log which is called temperature $\log$ is to determine the production and injection areas, investigate the procedure of making a fracture, and 
Table 1 Perforation intervals

\begin{tabular}{ll}
\hline $\begin{array}{l}\text { From the starting point of the perforated area } \\
(\mathrm{ft})\end{array}$ & $\begin{array}{l}\text { To ending point of } \\
\text { the perforated area } \\
(\mathrm{ft})\end{array}$ \\
\hline 6047.29 & 6059.15 \\
6096.35 & 6114.92 \\
6146.79 & 6158.57 \\
6205.62 & 6216.43 \\
6250.12 & 6263.51 \\
6293.54 & 6298.32 \\
\hline
\end{tabular}

detect gas entrance and movement of fluid flow at the back of the pipeline.

\section{Field description}

The studied field located in the Persian Gulf. In this oil field, six production wells and four water injection wells drilled. Production crude oil from this reservoir categorized in the highquality crude with the number of 44 API, which has the similar potential with Brent crude oil. This reservoir was one of the geophysical reservoirs in this field which the subsequences of drilled sections or layers typically considered. There was not seen any fault during the drilling procedures that may cause duplication or elimination of geological layers. Geological properties of each layer are as below:

1. Hith Formation from the depth of 1757-1847 m (average thickness: $90 \mathrm{~m}$ )

2. Surmeh Formation from the depth of 1847-2534 m (average thickness: $687 \mathrm{~m}$ )

Perforation intervals enter into the Emeraude software. To obtain this interval, reservoir areas derived from geological wellbore data. Perforation intervals are provided in Table 1.

The fluid properties of this reservoir are demonstrated in Table 2.

Production rates of each fluid at the surface are shown in Table 3 statistically.

\section{Core analysis}

For a start, the reservoir divided into six layers which had different permeability up to each section into 268 samples. According to this classification, six cores were taken from the layers, and the average permeability had been obtained for six cores in Table 4. To measure average permeability, the amount of this parameter is calculated in each layer in Table 4 .
Table 2 Fluid properties of this reservoir

\begin{tabular}{ll}
\hline Fluid type & Water, oil, gas \\
\hline Gas specific gravity & 1.162 \\
$\mathrm{~N}_{2} \%$ & 2.37 \\
$\mathrm{Co}_{2} \%$ & 1.08 \\
$\mathrm{H}_{2} \mathrm{~S} \%$ & 0 \\
$\mathrm{Z}$ & From Beggs and Brill, constrained Eq. \\
Oil specific gravity & $0.855 \mathrm{sp} \mathrm{gr}$ \\
$\mathrm{GOR}$ & $420.19 \mathrm{ft}^{3} / \mathrm{bbl}$ \\
$P_{b}$ & From Petroski and Farshad Eq. \\
$R_{s}$ & From Petroski and Farshad Eq. \\
$B_{O}$ & From Standing Eq. \\
$C_{o}$ & From Vasquez and Beggs Eq. \\
Water salinity & $2.5 \mathrm{E}+6$ \\
$R_{s w}$ & From Katz Eq. \\
$C_{w}$ & From Dodson and Standing Eq. \\
\hline
\end{tabular}

Table 3 Production rates of each fluid at the surface

\begin{tabular}{lcl}
\hline Type of fluid & Flow rate & Unit \\
\hline Water & 498 & STB/D \\
Oil & 518 & STB/D \\
Gas hydrocarbons & 90 & Mscf/D \\
\hline
\end{tabular}

Table 4 Amount of average permeability of each layer

\begin{tabular}{ll}
\hline Layer no. & $\begin{array}{l}\text { Average } \\
\text { permeability } \\
(\mathrm{mD})\end{array}$ \\
\hline Layer 1 & 122.3755195 \\
Layer 2 & 146.78836 \\
Layer 3 & 113.96074 \\
Layer 4 & 84.36438766 \\
Layer 5 & 142.9324114 \\
Layer 6 & 39.63111259 \\
\hline
\end{tabular}

\section{Permeability measurements by using Emeraude software}

The amount of skin effect due to the well production is assumed zero. The amount of flow rate is calculated from Darcy equation in the Software. External and internal wellbore radii were 4.5 and 2.25 inches, respectively. The software calculated the amount of viscosity via PVT data like bubble point pressure. The amount of permeability measurements by Emeraude Software is demonstrated statistically in Table 5.

To achieve more sustainable and reliable data, it needs to rearrange the core data efficiently; in respect of the way, by removing 7 percent of the high and low 
Table 5 Amount of permeability measurements by Emeraude software

\begin{tabular}{lc}
\hline Layer no. & $\begin{array}{l}\text { Permeability by } \\
\text { Emeraude software } \\
(\mathrm{mD})\end{array}$ \\
\hline Layer 1 & 76.419 \\
Layer 2 & 106.812 \\
Layer 3 & 72.51 \\
Layer 4 & 55.84 \\
Layer 5 & 99.12 \\
Layer 6 & 10.434 \\
\hline
\end{tabular}

Table 6 Comparison of permeability between two techniques after correcting core data analysis

\begin{tabular}{llc}
\hline Layers & $\begin{array}{l}\text { Average permeability of } \\
\text { each layer }\end{array}$ & $\begin{array}{l}\text { Permeability measure- } \\
\text { ments by Emeraude } \\
\text { software }\end{array}$ \\
\hline Layer 1 & 70.521 & 76.419 \\
Layer 2 & 98.51 & 106.812 \\
Layer 3 & 61.94 & 72.51 \\
Layer 4 & 78.651 & 55.84 \\
Layer 5 & 92.35 & 99.12 \\
Layer 6 & 21.514 & 10.434 \\
\hline
\end{tabular}

permeability from the received cores, core permeability intervals could be arranged between 0.12 and $370 \mathrm{mD}$. The reason for this elimination is that during the core plugging, the cores would be crushed from the bottom and top of the cores in the equipment, so to obtain appropriate results from core analysis, we assumed the right section of each cores which are not damaged. Furthermore, due to the laboratory investigation report from these cores, the percentages of damages for cores are calculated averagely about 5-10 percent, and we assumed the average number of 7 percent for them. Consequently, those permeabilities ranged out of these intervals would not be accepted and would not play a significant role in the calculation and should be negligible. It would be noticed that the reservoir may be produced from the permeable layer which has been omitted from the measurements. Thereby, regarding lack of image logs through the well logging, it would be assumed that these layers do not have a critical role in the productivity rate. This issue is, too, considered as one of the restrictions of using production logging tools in the carbonated reservoirs. The comparison of permeability between two techniques after correcting core data analysis is explained in Table 6.

The estimated flow rate from Emeraude software is demonstrated in Table 7. In some areas, the obtained flow
Table 7 Estimated flow rate from Emeraude software (bbl/D)

\begin{tabular}{lc}
\hline Layers & $\begin{array}{l}\text { Estimated flow rate } \\
\text { from Emeraude soft- } \\
\text { ware }\end{array}$ \\
\hline Layer 1 & -312.985 \\
Layer 2 & 427.407 \\
Layer 3 & 716.844 \\
Layer 4 & -76.212 \\
Layer 5 & -46.277 \\
Layer 6 & 1.858 \\
\hline
\end{tabular}

Comparison of Average Permeability in each Layer by Core analysis

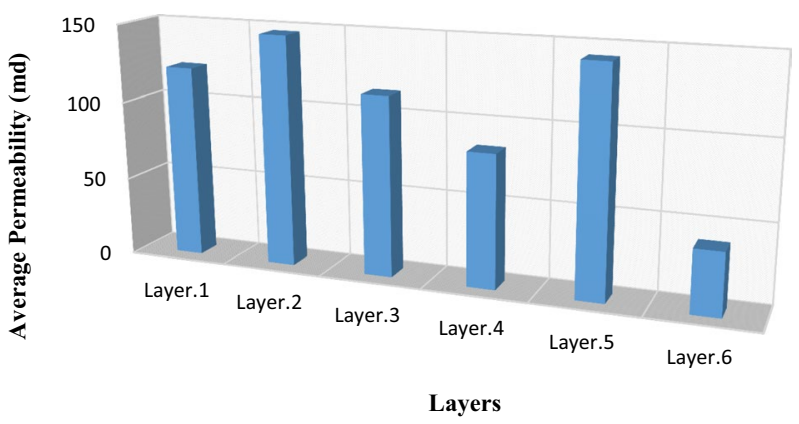

Fig. 5 Amount of average permeability of each layer

rate from Emeraude software was negative. The cause of this issue could be the occurrence of latitude flow between two productive layers or may be caused by high fluid velocity. This parameter might rotate the butterfly tools reversely.

\section{Results and discussion}

1. As can be seen in Fig. 5, the amount of permeability in the layers 2 and 5 are the highest (approximately $140 \mathrm{mD}$ ). It revealed that these layers had played the significant role in the production rate of the well. The lowest permeable area belonged to layer 6 ; it is just under $40 \mathrm{mD}$. On the contrary, by increasing the depth, the permeability of the reservoir would be decreased.

2. The amount of estimated permeability by Emeraude software is demonstrated in Table 5. It has the same pattern as core data analysis by increasing the depth. It has been provided in Fig. 6 .

3. The comparison of estimated permeability from both methodologies is plotted in Fig. 7. In all the layers, the amount of permeability has more than the amount of permeability which was obtained by Emeraude software. In the layers 3 and 4, these amounts are nearly close 
Permeability Measurements by Emeraude Software

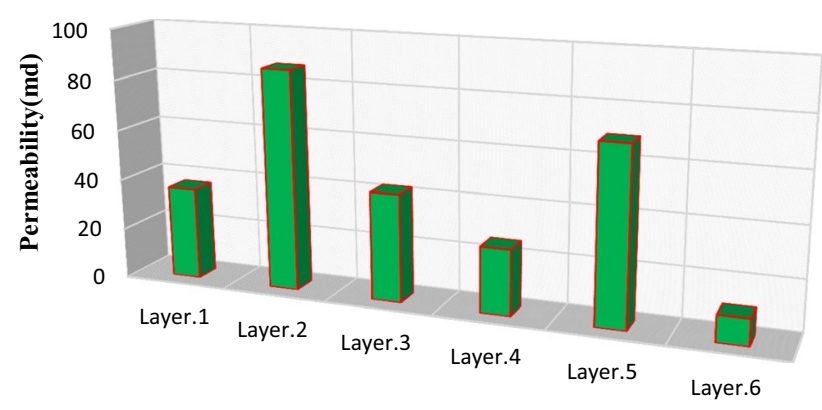

Layers together. Thereby, it needs to normalize the gathering data by eliminating the 7 percent of high and low permeabilities from each layer.

4. After normalizing and reducing the unnecessary data, it demonstrates that the amount of permeability in both methods in the layers $1,2,3$, and 5 is being relatively close to each other for both techniques. Therefore, regarding high expenditures of core analysis in the laboratory, production logging tools would be preferred to predict permeability. On the contrary, layers 4 and 6 have differences between two methods. Its comparison is plotted in Fig. 8.

Fig. 6 Permeability measurements by Emeraude software

Fig. 7 Comparison of permeability between two techniques
Fig. 8 Comparison of permeability between two techniques after correcting core data analysis
Comparison of permeability between two techniques

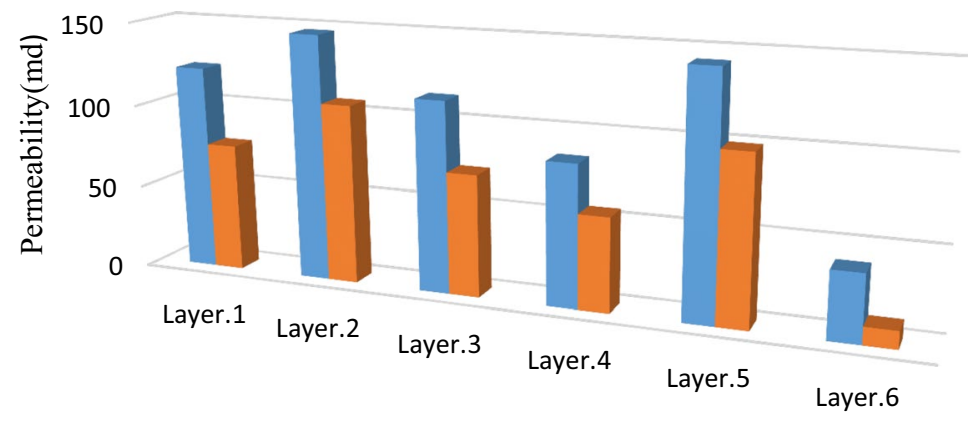

Layers

\section{Comparison of permeability between two techniques after correcting core data analysis}

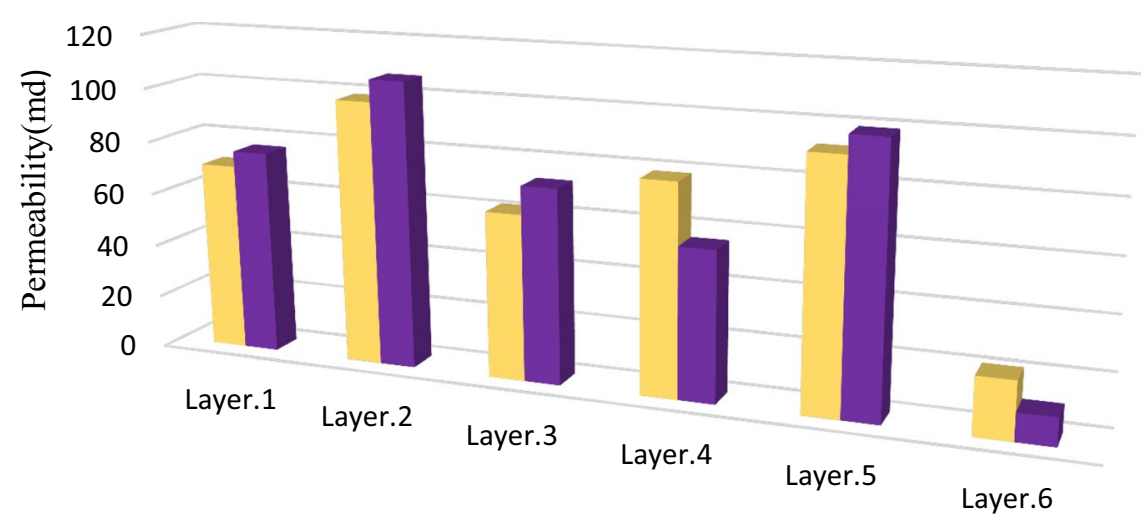

Layer

Comparison of Average Permeability in each Layer

- Permeability Measurements by Emeraude Software 


\section{Parameters would severely affect the results of PLT}

One of the significant parameters which play a vital role in the permeability measurements is external borders pressure. External reservoir borders at different depths have various pressures. It obtains the more appropriate quantities which they matched with core analysis, and the average pressure is assumed in the calculations. The accurate and efficient way to measure average pressure is selecting inflow performance (henceforth; SIP). Also, average pressure has an adverse effect on the permeability, and by increasing average pressure, permeability would decrease. Due to the results of SIP, it is evident that when the productivity index (PI) is very low, the PLT is not preferable for permeability measurements and core analysis would be the best choice. The second significant parameter is the bottom hole pressure, which exercises a dominant influence on the permeability; to dramatically increase the permeability by raising the bottom hole pressure. Hence, this parameter should be taken into account throughout the logging procedures, and its changes should be recorded accurately. The other parameters such as fluid properties (e.g., viscosity, oil formation volume factor, etc.) except pressure gradient and fluid velocity have less impact on the permeability measurements and should be negligible.

\section{Conclusion}

Using production logging tools has some possibilities like a homogeneous reservoir, single-phase flow, and the stable system should appear on the reservoir system. One of the chief aims of production logging tools is to eliminate the small-scale non-homogeneity principals of cable logs. Moreover, it calibrates their homogeneity extremity. This technique could enroll as depth interval detection in those layers which have more permeability regarding immediate alterations in the well flow logs. Therefore, these inefficiencies may not be illustrated by core plugs and cable logs. The most extraordinary appeal of production logging tools is to obtain the appropriate vertical dispersion of the reservoir layers, which helps to the accurate explanation of flow units in the reservoir. In the areas with a low volume of flow rate or low productivity index, it would not be preferred to utilize production logging tools instead of core analysis. Production logging tools have been more reliable and better results when the flow rate does not low enough regarding rotation of the tools.

\section{Suggestions and future research}

1. We highly recommend investigating more wells and fields to get proper evaluations from them.

2. During the use of production logging tools, it would be better to apply FMI and VSP tools to obtain more accurate data.

3. By using MATLAB software regarding the appropriate artificial network algorithms to simulate the proper way of fluid mobilization, it would be achieved an analytical model for estimating the amount of permeability in fractured reservoirs which facilitate the petroleum industries to foster a deeper understanding of reservoir fluid characterization.

Open Access This article is distributed under the terms of the Creative Commons Attribution 4.0 International License (http://creativecomm ons.org/licenses/by/4.0/), which permits unrestricted use, distribution, and reproduction in any medium, provided you give appropriate credit to the original author(s) and the source, provide a link to the Creative Commons license, and indicate if changes were made.

\section{References}

Adeboye Y, Ubani C, Farayola K (2012) Permeability estimation and hydraulic zone pore structures identification using core and well logs data. Pet Coal 54(1):52

Aghli G, Soleimani B, Moussavi-Harami R, Mohammadian R (2016) Fractured zones detection using conventional petrophysical logs by differentiation method and its correlation with image logs. J Pet Sci Eng 142(Supplement C):152-162. https://doi.org/10.1016 /j.petrol.2016.02.002

Aigbedion I (2007) A case study of permeability modeling and reservoir performance in the absence of core data in the Niger Delta, Nigeria. J Appl Sci 7(5):772-776

Ali Ahmadi M, Zendehboudi S, Lohi A, Elkamel A, Chatzis I (2013) Reservoir permeability prediction by neural networks combined with hybrid genetic algorithm and particle swarm optimization. Geophys Prospect 61(3):582-598. https://doi.org/10.1111/j.1365 $-2478.2012 .01080 . \mathrm{x}$

Al-Mulhim A, Al-Thwaiqib I, Bogari A, Bawazir M, Abdein M (2015) Integrated production logging approach for successful leak detection between two formations: a case study. Paper presented at the SPE annual technical conference and exhibition

Amir Shah J, Aminuddin M, Fatah A, Fyfe D, Justin M (2017) Enhanced efficiency in deep water testing operations delivered by smart DST string. Paper presented at the SPE/IATMI Asia Pacific oil and gas conference and exhibition

Cui J, Zhu D, Jin M (2016) Diagnosis of production performance after multistage fracture stimulation in horizontal wells by downhole temperature measurements. SPE Prod Oper 31(04):280-288

Dale C (1949) Bottom hole flow surveys for determination of fluid and gas movements in wells. J Pet Technol 1(08):205-210

Denney D (2007) Core-data preprocessing to improve permeability estimation from logs. J Pet Technol 59(05):47-50

Feng R, Harpalani S, Pandey R (2017) Evaluation of various pulsedecay laboratory permeability measurement techniques for highly 
stressed coals. Rock Mech Rock Eng 50(2):297-308. https://doi. org/10.1007/s00603-016-1109-7

Frash LP, Carey JW, Lei Z, Rougier E, Ickes T, Viswanathan HS (2016) High-stress triaxial direct-shear fracturing of Utica shale and in situ X-ray microtomography with permeability measurement. J Geophys Res Solid Earth 121(7):5493-5508. https://doi. org/10.1002/2016JB012850

Frooqnia A, Torres-Verdín C, Sepehrnoori K (2011) Numerical simulation and interpretation of production logging measurements using a new coupled wellbore-reservoir model. Paper presented at the SPWLA 52nd annual logging symposium

Galvao MS, Guimaraes CS (2017) A new method for calculating individual layer permeability and skin in a multilayered reservoir using production logging data: the delta transient method. Paper presented at the SPE Latin America and Caribbean mature fields symposium

Gan T, Balmain B, Sigbatullin A (2016) Formation evaluation logoff results comparing new generation mining-style logging tools to conventional oil and gas logging tools for application in coalbed methane (CBM) field development. J Nat Gas Sci Eng 34(Supplement C):1237-1250. https://doi.org/10.1016/j.jngse.2016.07.070

Grayson S, Kohring J, Elliot W, Hertfelder G, Goeres T, Horner S (2002) Production logging advances in the fractured monterey. Paper presented at the SPE Western Regional/AAPG Pacific section joint meeting

Haoua TB, AbuBakr S, Pazzi J, Djessas L, Ali A, Ayyad H, Boumali A, Boulkaila Z, Brahim M (2015) Combining horizontal production logging and distributed temperature interpretations to diagnose annular flow in slotted-liner completions. Paper presented at the SPE Middle East oil and gas show and conference

Haro CF (2004) The perfect permeability transform using logs and cores. Paper presented at the SPE annual technical conference and exhibition

Hoffman BT, Narr W (2012) Using production logs (PLT) to estimate the size of fracture networks. J Pet Sci Eng 98-99(Supplement C):11-18. https://doi.org/10.1016/j.petrol.2012.08.019

Huang YF, Chiueh PT, Kuan WH, Lo SL (2013) Pyrolysis kinetics of biomass from product information. Appl Energy 110(Supplement C):1-8. https://doi.org/10.1016/j.apenergy.2013.04.034

Huang G, Song H, Cao Y, Yang J, Wang Y, Killough J, Cai S (2016) Numerical investigation of low-velocity non-Darcy flow of gas and water in coal seams. J Nat Gas Sci Eng 34(Supplement C):124-138. https://doi.org/10.1016/j.jngse.2016.06.047

Kading HW (1976) Horizontal-spinner, a new production logging technique. Log Anal 17(05):3-7

Kaitna R, Palucis MC, Yohannes B, Hill KM, Dietrich WE (2016) Effects of coarse grain size distribution and fine particle content on pore fluid pressure and shear behavior in experimental debris flows. J Geophys Res Earth Surf 121(2):415-441. https://doi. org/10.1002/2015JF003725

Kundu P, Kumar V, Mishra IM (2016) Experimental and numerical investigation of fluid flow hydrodynamics in porous media: characterization of pre-Darcy, Darcy and non-Darcy flow regimes. Powder Technol 303(Supplement C):278-291. https://doi. org/10.1016/j.powtec.2016.09.037

Lee MY, Bauer SJ (2016) Development of helium-mass-spectrometrypermeameter for the measurement of permeability of near-impermeable rock. Rock Mech Rock Eng 49(12):4661-4665. https://doi. org/10.1007/s00603-016-1058-1
Li M, Zhao Y (2014) Chapter 9 - Hydrocarbon reservoir logging evaluation methods and technologies. In: Geophysical exploration technology. Elsevier, Oxford, pp 239-303

McCain WD, Spivey JP, Lenn CP (2011) Petroleum reservoir fluid property correlations. PennWell Books, Houston

Miklashevskiy D, Shako V, Borodin I, Mukhin V, Skochelyas R, Shalamov V, Valiullin R, Iarullin R (2017) New production logging tool for inflow profiling of low-rate oil and water horizontal wells: case studies of field testing an experimental prototype. Soc Pet Eng. https://doi.org/10.2118/187901-MS

Muljadi BP, Blunt MJ, Raeini AQ, Bijeljic B (2016) The impact of porous media heterogeneity on non-Darcy flow behaviour from pore-scale simulation. Adv Water Resour 95(Supplement C):329_ 340. https://doi.org/10.1016/j.advwatres.2015.05.019

Plastino A, Gonçalves EC, da Silva PN, Carneiro G, de Vasconcellos Azeredo RB (2017) Combining classification and regression for improving permeability estimations from $1 \mathrm{H}$ NMR relaxation data. J Appl Geophys 146(Supplement C):95-102. https://doi. org/10.1016/j.jappgeo.2017.09.003

Prada A, Civan F (1999) Modification of Darcy's law for the threshold pressure gradient. J Pet Sci Eng 22(4):237-240. https://doi. org/10.1016/S0920-4105(98)00083-7

Qobi L, De Kuijper A, Tang XM, Strauss J, Munkholm M (2000) Permeability determination from stoneley waves in the Ara Group. Paper presented at the SPE annual technical conference and exhibition

Quintero L, Boyd A, Gyllensten A, El-Wazeer F (1999) Comparison of permeability from NMR and production analysis in carbonate reservoirs. Paper presented at the SPE annual technical conference and exhibition

Rafik B, Kamel B (2017) Prediction of permeability and porosity from well $\log$ data using the nonparametric regression with multivariate analysis and neural network, Hassi R'Mel Field, Algeria. Egypt J Pet 26(3):763-778. https://doi.org/10.1016/j.ejpe.2016.10.013

Sætrom J, Selseng H, MacDonald A, Kjølseth T, Kolbjørnsen O (2016) Consistent integration of drill-stem test data into reservoir models on a giant field offshore Norway. Paper presented at the SPE annual technical conference and exhibition

Sullivan MJ (2007) Permeability from production logs-method and application. J Pet Technol 59(07):80-87

Wang X, Sheng JJ (2017) Discussion of liquid threshold pressure gradient. Petroleum 3(2):232-236. https://doi.org/10.1016/j.petlm.2017 .01 .001

Williams B (2016) Verifying permeability distribution using interventionless production logging technology. Paper presented at the Arctic technology conference

Wilson A (2016) Production-logging tools facilitate well testing in challenging environments. J Pet Technol 68(02):79-80

Xiong Y, Yu J, Sun H, Yuan J, Huang Z, Wu Y (2017) A new NonDarcy flow model for low-velocity multiphase flow in tight reservoirs. Transp Porous Media 117(3):367-383. https://doi. org/10.1007/s11242-017-0838-8

Publisher's Note Springer Nature remains neutral with regard to jurisdictional claims in published maps and institutional affiliations. 